\title{
Research on Evaluation of Agricultural Planting Security in Hebei Province
}

\author{
Li Deng and Yali Li \\ Department of Economic and Management, Tangshan College, \\ Hebei, P.R. China \\ Dengli20072005@126.com
}

\begin{abstract}
Hebei agricultural planting security is relative to the agricultural products of the consumer safety of the whole province and the beijing-tianjin region of. This paper selects agricultural planting safety as the research object of products and focus on the characteristics of the agricultural products plant. This paper applies theory and method of system comprehensive evaluation to screen index of agricultural planting evaluation, in order to building evaluation model of agricultural planting safety. This paper abides by the principle of qualitative analysis with quantitative analysis, applies the method of AHP scheduling comprehensive ranking of each index, scientifically evaluates planting security system of agricultural products in Hebei province. The purpose of this paper is to provide the scientific basis in Hebei province for improving agricultural planting security policy.
\end{abstract}

Keywords: Agricultural planting security, Evaluation system, AHP.

\section{Introduction}

Along with the progress of science and technology of agriculture, the unit output and total production of agricultural commodities improve continuously, agricultural ended its economic shortage, appeared the situation of total balance and surplus in good years. The demand of consumers for agricultural production has been changed from pursuing the number to the pursuiting of quality and safety. Hebei is a big agricultural province with agricultural product variety, large output, links, chain long, low degree of organization, the heavy responsibility of safety supervision, and the special geographic position of encircling the beijing-tianjin and special status of supplying beijing-tianjin agricultural commodities. Therefore, evaluate agricultural planting scientific and objectively, strengthen planting safety of agricultural products globally, to guarantee the safety of agricultural planting, and ensure that the province and the beijing-tianjin region agricultural products consumer safety has the important practical significance. 


\section{Model Design}

\subsection{Specification of a Model}

According to the requirements of good agriculture practice, combine with the actual situation of evaluation of agricultural planting site. From the angle of farm produce safety management, the evaluation index system will include five aspects these are land usage, soil analysis detection, irrigation water, management of environment problem and the validity of the planting site management system. This paper also establish further evaluation index of pass class time structure (as it is shown in table 1).

Table 1. Evaluation System of Agricultural Planting Security in Hebei Province

\begin{tabular}{ccc}
\hline Target laver & Primarv index & Secondarv index \\
\hline Evaluation & Soil analysis detection (B1) & Controlling of pesticides residues(C1) \\
& & Controlling of heavy metal(C2) \\
System & Nutrient content(C3) \\
& Irrigation water (B2) & Adequacy of the water(C4) \\
of & & Quality of water (C5) \\
& Management of & Controlling of pollution(C6) \\
Agricultural & environment problem(B3) & Surrounding environment (C7) \\
& & Protection of ecological environment(C8) \\
Planting & Validity of land & Protection of resources(C9) \\
& management system (B4) & Techology management(C10) \\
Security & & Fertilizer usage(C12) \\
\hline
\end{tabular}

\subsection{Build Judgment Matrix}

The effects of these four indicators are different to the agricultural planting security in Hebei Province. Based on this, considering the differences of Hebei province, this paper used questionnaires to visit different experts and relevant management department in order to get the data of evaluation system of agricultural planting safety in Hebei. First order judgment matrix and second order judgment matrix was built based on the indicators above.

\subsection{Weight Calculation of Single Hierarchy and Consistency Test}

Eigenvalues and eigenvectors were calculated by AHP Software. The weight sorting results of each effect factor were listed in the table 2 and table 3 . The results of each matrix of the consistency test were listed in the bottom of each table. 
Table 2. First Order Judgment Matrix

\begin{tabular}{cccccc}
\hline A & B1 & B2 & B3 & B4 & Sort Weight \\
\hline B1 & 1 & $1 / 2$ & 2 & 3 & 0.278 \\
B2 & 2 & 1 & 3 & 4 & 0.467 \\
B3 & $1 / 2$ & $1 / 3$ & 1 & 2 & 0.160 \\
B4 & $1 / 3$ & $1 / 4$ & $1 / 2$ & 1 & 0.095 \\
\hline
\end{tabular}

The effect size of various indicators in evaluation system of agricultural planting security in Hebei province could be determined from table 2. The result of operation was $\lambda \max =4.031, \mathrm{CI}=0.010, \mathrm{RI}=0.900, \mathrm{CR}=0.011<0.1$, so the test of consistency passed. Results showed that the top one of weight sort was the irrigation water (with the value of 0.467 ), which played an important part in this group. The second one of weight sort was the Soil analysis detection, and it was 0.278 . The sum of two was 0.745 .

Table 3. Second Order Judgment Matrix

\begin{tabular}{ccccc}
\hline B1 & C1 & C2 & C3 & Sort Weight \\
\hline C1 & 1 & 2 & $1 / 3$ & 0.230 \\
C2 & $1 / 2$ & 1 & $1 / 5$ & 0.122 \\
C3 & 3 & 5 & 1 & 0.648 \\
\hline
\end{tabular}

From table 3, we can determine the contribution size of controlling of pesticides residues, controlling of heavy metal, nutrient content, $\lambda \max =3.004, \mathrm{CI}=0.002$, $\mathrm{RI}=0.580, \mathrm{CR}=0.003<0.1$, so the test of consistency passed. Results showed that the greatest impact on soil analysis detection is nutrient content, and the weight sort is 0.648 . The second one of weight sort was the soil analysis detection, the weight sort is 0.230 . The sum of the two is 0.878 .

Table 3. (Continuation Sheet 1)

\begin{tabular}{ccccc}
\hline B2 & C4 & C5 & C6 & Sort Weight \\
\hline C4 & 1 & 3 & 4 & 0.614 \\
C5 & $1 / 3$ & 1 & 3 & 0.268 \\
C6 & $1 / 4$ & $1 / 3$ & 1 & 0.117 \\
\hline
\end{tabular}

The contribution size of adequacy of the water, quality of water and controlling of pollution in irrigation water could be determined from table 3 (Continuation Sheet 1). $\lambda \max =3.074, \mathrm{CI}=0.037, \mathrm{RI}=0.508, \mathrm{CR}=0.064<0.1$, so the test of consistency passed. Results showed that the greatest impact in irrigation water is adequacy of the water, and the weight sort is 0.614 , the sum of the other two is 0.385 . 
Table 3. (Continuation Sheet 2)

\begin{tabular}{ccccc}
\hline B3 & C7 & C8 & C9 & Sort Weight \\
\hline C7 & 1 & 2 & 5 & 0.582 \\
C8 & $1 / 2$ & 1 & 3 & 0.309 \\
C9 & $1 / 5$ & $1 / 3$ & 1 & 0.109 \\
\hline
\end{tabular}

The contribution size of surrounding environment, protection of ecological environment and protection of resources in management of environment problem could be determined from table 3(Continuation Sheet 2). $\lambda \max =3.004, \mathrm{CI}=0.002, \mathrm{RI}=0.580$, $\mathrm{CR}=0.003<0.1$, the test of consistency passed. Results showed that the greatest impact in management of environment problem is surrounding environment, the weight sort is 0.582 .

Table 3. (Continuation Sheet 3)

\begin{tabular}{cccccc}
\hline B4 & C10 & C11 & C12 & C13 & Sort Weight \\
\hline C10 & 1 & $1 / 2$ & $1 / 3$ & $1 / 4$ & 0.095 \\
C11 & 2 & 1 & $1 / 2$ & $1 / 3$ & 0.160 \\
C12 & 3 & 2 & 1 & $1 / 2$ & 0.278 \\
$\mathrm{C} 13$ & 4 & 3 & 2 & 1 & 0.467 \\
\hline
\end{tabular}

The contribution size of technology management, identification and traceability management, fertilizer usage and protection ofcrops could be determined from table 3 (Continuation Sheet 3). $\lambda \max =4.031, \mathrm{CI}=0.010, \mathrm{RI}=0.900, \mathrm{CR}=0.011<0.1$, the test of consistency passed. Results showed that the greatest impact in validity of land management system is protection of crops. he weight sort is 0.467 . The second one of weight sort was fertilizer usage, the weight sort is 0.278 , the sum of the other two is 0.745 .

\subsection{Weight Calculation of Overall Hierarchy and Consistency Test}

$\mathrm{CI}=0.019, \mathrm{RI}=0.610, \mathrm{CR}=0.031<0.1$, so the test of consistency passed. From table 4, the conclusion that the top three indexes are adequacy of the water, quality of water and nutrient content could be drawn. Results showed that the important position in agricultural planting security system of Hebei province is ensuring sufficient irrigation water, and water quality is also very important, both of them become the most important factors in evaluation system. 
Table 4. Overall Hierarchy

\begin{tabular}{cccccc}
\hline A & B1 & B2 & B3 & B4 & Sort Weight \\
\hline C1 & 0.230 & & & & 0.064 \\
C2 & 0.122 & & & & 0.034 \\
C3 & 0.648 & & & & 0.108 \\
C4 & & 0.614 & & & 0.287 \\
C5 & & 0.268 & & & 0.125 \\
C6 & & 0.117 & & & 0.055 \\
C7 & & & 0.582 & & 0.093 \\
C8 & & & 0.309 & & 0.050 \\
C9 & & & 0.109 & & 0.018 \\
C10 & & & & 0.095 & 0.009 \\
C11 & & & & 0.160 & 0.015 \\
C12 & & & & 0.278 & 0.026 \\
C13 & & & & 0.467 & 0.044 \\
\hline
\end{tabular}

\section{Conclusions and Recommendations}

Lake of irrigation water resource directly leads to reduce agricultural water and restricts to establish the system of agricultural products plant safety; the more serious of water pollution makes water quality can't satisfy the requirements of agricultural irrigation and influences the growth of agricultural products quality. So agricultural planting should stay away from the pollution sources, in order to ensuring the quality of irrigation water source. Organic production technology and regulatory rules should be used gradually to improve water resources environment and make them comply with the agriculture standard; in the production practice. The surrounding water pipe buried should strengthen in order to ensuring the clean water of irrigation.

Strengthen the supervision of agricultural input products. With pesticides and additives for key, the government should put an end to the production and sales illegal pesticides and poisonous and harmful chemicals. Strengthened supervision and inspection which is the quality of pesticide products in production enterprise and standard management of pesticide labels and effective component content should also be emphasized.

Focus on the requirements which are the environment quality of agricultural products whether meet the production safety of agricultural products should be focus on. Analysis the pollution source of agricultural products, based on geographic information system establish regional soil database. Professional evaluation model of regional soil for environmental quality assessment should be used in order to conclude that fit for a regional development of the species of agricultural products.

Compulsory for agricultural planting process setting up production records, in order to laying the foundation of back of agricultural planting security; guide and supervise of quality and safety of agricultural products self inspections through each production 
main body, ban unqualified agricultural products on the market, adopt technology of bar code, consumers can rapidly inquire agricultural planting files, So as to realize the rest assured consumption.

\section{References}

1. Zhang, H., Sun, X., Liu, Y., Liu, J.: Research on the Feedback System for Quality and Safety of Agricultural Products. J. Hubei Agricultural Sciences (2010)

2. Zhou, Y., Deng, C.: Quality-safety Situation and Development Suggestions of Agricultural Products in Liaoning Province. J. Agricultural Economy (2011)

3. Gao, S.: Problems and CountermEasures in Agricultural Product Quality Security Management System in China. Agricultural University of Henan (2009)

4. Zhang, Y.: Study on Status and Development of Agro-food Quality and Safety Management in Jiangsu Province. University of Yangzhou (2009) 